\title{
Studien über den Energiewechsel und die Blutveränderungen bei eingeschränkter Atemfläche.
}

\author{
II. \\ Veränderung der Blutkonzentration bei eingeschränkter \\ Atemfäche. \\ Von \\ Jusaburo Yoshida. \\ (喈田量三郎) \\ (Aus der Medizinischen Klinik von Prof. Dr. T. Kato an der \\ Kaiserlichen Universität zu Sendai.)
}

In der ersten Mitteilung habe ich ${ }^{1}$ bemerkt, dass Beschränkung der Atemfläche auf den Gasaustausch Einfluss ausübt. Dass Gas- und Wasseraustausch in innigem Zusammenhang miteinander stehen, das kann man auch aus der Betrachtung der Beziehungen der Lunge zum Wasseraustausch erkennen. Und weil die Lunge, wie die Leber, mit einem grossen Gefässystem durchsetzt ist, das viel Blut enth:̈lt, kann man sich vorstellen, dass Kompression oder Bewegungsbeschränkung der Lunge auf die Wasserverschiebung im Blute irgendwie einwirkt. In der diesbezüglichen Literatur wird nichts Genaueres darüber berichtet, welchen Einfluss die beschränkte Atemfläche auf den Wasseraustausch ausübt. Deshalb habe ich in dieser Mitteilung bei normalen Tieren sowie bei solchen, die durch Nieren- bzw. Vornierengifte vergiftet waren und schon gestörten Wasseraustausch zwischen Gewebe und Blut bzw. Blut und Niere aufwiesen, diese Frage behandelt.

\section{Methodik.}

Zum Experiment habe ich Kaninchen verwendet. Über die die Einschränkung der Atemfläche betreffende Methodik habe ich schon in der ersten Mitteilung1) ausfiuhrlich gesprochen : Eine der Methoden ist Injektion von flüssigem Paraffin in die einseitige Pleu-

1) Yoshida, Tohoku Journ. Exp. Med., 1929, 15, 385. 
rahöhle, die andere die Einschiebung einer $\mathrm{K}$ anile in den einseitigen Hauptbronchus zur Ausschaltung der anderen ganzen Lunge ron der Atmung.

Zuerst habe ich, gleich nachdem ich das Blut der Kontrolle erhalten batte, die Atenflïche lege artis beschränkt und dann je nach 1,5, 10, 20,30,60,90 und 120 Minuten mit der Tuberkulinspritze aus den beiderseitigen $A$. femoralis Blut entnomnen, und 2 war aus jeder $0,7-0,8 \mathrm{~cm}$. Von dem auf diese Weise entnommenen Blut habe ich den Hümoglobingehalt nit dem Fleischl-M iescherschen Hämometer, den Serunejweisgehalt mit dem Pulfrichschen Fintauchrefraktometer und den Serumkochsalzgehalt nach der Ruszn yákschen') Methode bestimmt.

In diesem Experiment habe ich, wie oben erwïhnt, jedesmal nur die geringe Menge Blut $(0,7-0,8 \mathrm{ccm})$ entnommen, um Anümie bei den Tieren möglichst zu vermejden. Da aber nach der Art dieses Experiments die ganze Menge des neunmal entnommenen Bluts eines Tiers ca. 6-7 ccm beträgt, so fragt es sich, welchen Einfluss dies auf die Blutkonzentration ausübt. Ich habe zur Kontrolle 4 gesunden Kaninchen, in denselben Intervallen genau wie beim Hauptexperimente neunmal Blut entnommen und das Serumeiweiss-, Häroglobin- und Serumkochsalzgehalt ermittelt. Wie in Tab. 1 und Fig. 1 gezeigt, tritt, wenn man die nur 0,7-0,8 ccm betragende Blutentnahme neunmal wiederholt hat, mässige Blutverdünnung ein, d. h. Eiweiss und Hämoglobin nehmen ab, ihre Kurven senken sich allmählich. Obwohl Hämoglobin und Serumeiweiss beide zusammen abnehmen, ist der Grad der A bnahme des ersteren grösser als der des letzteren. Dies wird wahrscheinlich dadurch hervorgerufen, dass mit der Zunahme der Anämie Bluteiweisskörper sich quantitativ und qualitativ verändern und auch die Permeabilitüt der Gefüsswand für das Eiweiss u. a. sich verïndert. Also jedenfalls verursacht die Wiederholung der Blutentnahme, mag sie auch an sich gering sein, unvermeidlich entsprechende Blutverdünnung, d.h. Abnahme des Hämoglobins und Serumeiweisses. Diese Tatsache zog ich bei der Ausführung des Hauptexperiments in Betracht.

Ausser der obigen Bestimmung habe ich noch das Gesamtblutvolum gemessen, um den Mechanismus der Blutveränderung zu untersuchen.

Zur Bestimmung des Gesamtblutrolums habe ich die Motekische ${ }^{3)}$ Modifikation ron Fering a- und Creveld scher Kongorotmethode angewandt. Die Hauptsache bei ihrer Abänderung besteht darin, dass man den Kontrollfarbstoff mit der das Plasma des Kaninchens enthaltenden, ca. 1\%igen Stärkelösung und das den zu prüfenden Farbstoff enthaltende Plasma mit Aqua dest. verdiunnt.

Als Störung des Wasseraustauschs hervorrufende Gift habe ich Uran und Cantharidin gewählt. Ich habe Kaninchen subkutan prokg Körper-

2) Rusznyak, Biochem. Zeitschr., 1921, 114, 23.

3) Moteki, Nippon-Naika-Gakkai-Zasshi, 1925, 13, 121 (jap.).

4) Feringa und Creveld, Ref: Berichte iber die ges. Physiol, 1922, 10, 246. 
Tabelle 1.

Einfluss mehrmaliger Blutentnahme auf die Blutkonzentration.

\begin{tabular}{|c|c|c|c|c|c|c|c|}
\hline \multirow{2}{*}{ Nr. } & \multirow{2}{*}{$\begin{array}{c}\text { Körper- } \\
\text { gewicht } \\
\text { (kg) u. } \\
\text { Gesch- } \\
\text { lecht }\end{array}$} & \multirow{2}{*}{$\begin{array}{l}\text { Zeit der } \\
\text { Blut- } \\
\text { entnahme } \\
\text { (Min.) }\end{array}$} & \multicolumn{2}{|c|}{$\begin{array}{l}\text { Hümoglobin } \\
\text { d. art. Blutes }\end{array}$} & \multicolumn{2}{|c|}{$\begin{array}{l}\text { Serumeiweiss } \\
\text { d. art. Blutes }\end{array}$} & \multirow{2}{*}{$\begin{array}{l}\text { Serum- } \\
\mathrm{N}: \mathrm{Cl} \mathrm{d} . \\
\text { art. Blutes } \\
\mathrm{g} / \mathrm{dl}\end{array}$} \\
\hline & & & $\mathrm{g} / \mathrm{dl}$ & $\begin{array}{l}\text { Differenz } \\
\text { in } \%\end{array}$ & $\mathrm{~g} / \mathrm{dl}$ & $\begin{array}{c}\text { Differenz } \\
\text { in } \%\end{array}$ & \\
\hline 1 & $\begin{array}{c}2,200 \\
0\end{array}$ & $\begin{array}{r}0 \\
1 \\
5 \\
10 \\
20 \\
30 \\
60 \\
90 \\
120 \\
\end{array}$ & $\begin{array}{l}12,24 \\
12,24 \\
11,96 \\
11,96 \\
11,66 \\
11,66 \\
11,66 \\
11,36 \\
11,08\end{array}$ & $\begin{array}{l} \pm \quad 0 \\
-2,3 \\
-2,3 \\
-4,7 \\
-4,7 \\
-4,7 \\
-7,2 \\
-9,5\end{array}$ & $\begin{array}{l}5,858 \\
5,858 \\
5,815 \\
5,771 \\
5,684 \\
5,684 \\
5,684 \\
5,442 \\
5,401 \\
\end{array}$ & $\begin{array}{l} \pm 0 \\
-0,7 \\
-1,5 \\
-3,0 \\
-3,0 \\
-3,0 \\
-7,1 \\
-7,8 \\
\end{array}$ & $\begin{array}{l}0,670 \\
0,670 \\
0,670 \\
0,664 \\
0,664 \\
0,663 \\
0,675 \\
0,701 \\
0,704 \\
\end{array}$ \\
\hline 2 & $\begin{array}{c}1,950 \\
\hat{\delta}\end{array}$ & $\begin{array}{r}0 \\
1 \\
5 \\
10 \\
20 \\
30 \\
60 \\
90 \\
120 \\
\end{array}$ & $\begin{array}{l}12,52 \\
12,52 \\
12,24 \\
11,96 \\
11,66 \\
11,66 \\
11,50 \\
11,96 \\
11,96\end{array}$ & $\begin{array}{r} \pm 0 \\
-2,3 \\
-4,5 \\
-6,9 \\
-6,9 \\
-8,1 \\
-9,3 \\
-9,3\end{array}$ & $\begin{array}{l}5,837 \\
5,837 \\
5,749 \\
5,706 \\
5,662 \\
5,581 \\
5,488 \\
5,466 \\
5,488\end{array}$ & $\begin{array}{l} \pm 0 \\
\pm 1,5 \\
-2,2 \\
-3,0 \\
-5,2 \\
-6,0 \\
-6,4 \\
-6,0\end{array}$ & $\begin{array}{l}0,620 \\
0,620 \\
0,614 \\
0,604 \\
0,575 \\
0,577 \\
0,579 \\
0,587 \\
0,597\end{array}$ \\
\hline 8 & $\begin{array}{c}2,100 \\
0 \\
0\end{array}$ & $\begin{array}{r}0 \\
1 \\
5 \\
10 \\
20 \\
20 \\
60 \\
90 \\
120 \\
\end{array}$ & $\begin{array}{l}11,96 \\
11,96 \\
11,81 \\
11,66 \\
11,36 \\
11,22 \\
11,22 \\
10,94 \\
10,94\end{array}$ & $\begin{array}{l} \pm 0 \\
-1,3 \\
-2,5 \\
-5,0 \\
-6,2 \\
-6,2 \\
-8,5 \\
-8,5 \\
\end{array}$ & $\begin{array}{l}5,728 \\
5,706 \\
5,684 \\
5,619 \\
5,5: 1 \\
5,488 \\
5,488 \\
5,444 \\
5,379 \\
\end{array}$ & $\begin{array}{l}-0,4 \\
-0,8 \\
-1,9 \\
-3,4 \\
-4,2 \\
-4,2 \\
-6,7 \\
-6,1 \\
\end{array}$ & $\begin{array}{c}0,534 \\
0,534 \\
0,523 \\
0,523 \\
0,522 \\
0,514 \\
0,517 \\
0,534 \\
0,534\end{array}$ \\
\hline 4 & $\begin{array}{c}1,850 \\
8\end{array}$ & $\begin{array}{r}0 \\
1 \\
5 \\
10 \\
20 \\
30 \\
60 \\
90 \\
120\end{array}$ & $\begin{array}{l}13,36 \\
13,36 \\
13,08 \\
12,80 \\
12,58 \\
12,38 \\
12,38 \\
12,24 \\
12,24\end{array}$ & $\begin{array}{l} \pm 0 \\
-2,1 \\
-4,2 \\
-6,3 \\
-7,3 \\
-7,3 \\
-8,3 \\
-8,3\end{array}$ & $\begin{array}{l}6,336 \\
6,336 \\
6,314 \\
6,206 \\
6,120 \\
6,120 \\
5,902 \\
5,924 \\
5,858\end{array}$ & $\begin{array}{l} \pm 0 \\
-0,3 \\
-2,1 \\
-3,4 \\
-3,4 \\
-6,8 \\
-6,5 \\
-7,5\end{array}$ & $\begin{array}{l}0,554 \\
0,552 \\
0,549 \\
0,558 \\
0,554 \\
0,547 \\
0,549 \\
0,565 \\
0,565\end{array}$ \\
\hline
\end{tabular}

Fig. 1.

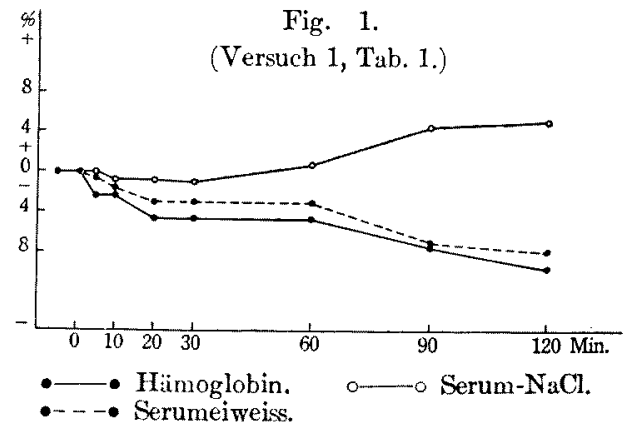

gewicht $0,5 \mathrm{ccm} 5 \%$ igen Uranylnitrats resp. 0,5 cem 0,1\% igen Cantharidins injiziert; bei Urankaninchen habe ich nach ca. 40 Stunden, bei Cantharidinkaninchen nach ca. 20 Stunden den Hurn untersucht und nur mit 
genügend vergifteten Füllen experimentiert (Tab. 1 und Fig. 1).

Versuchsergebnisse.

1. Bei künstlichem Paraffinothorax.

(a) Versuch im gesunden Zustand.

Hierzu wurden 7 Versuche ausgeführt. Als ich nach Injektion von 16-18 ccm Paraffinum fluidum pro kg Körpergewicht in die rechte Pleurahöhle des Kaninchens den Hämoglobin-, Serumeiweiss- und Serumkochsalzgehalt des Bluts nach je 1, 5, 10, 20, 30, 60, 90 und 120 Minuten untersuchte, fand ich in allen Versuchen im grossen und ganzen gleiche Resultate (Tab. 2).

Tabelle 2.

Verïnderung der Blutkonzentration durch Anlegen des Paraffionthorax bei normalen Kaninchen.

\begin{tabular}{|c|c|c|c|c|c|c|c|}
\hline \multirow{2}{*}{ Nr. } & \multirow{2}{*}{$\begin{array}{l}\text { Körper- } \\
\text { gewicht } \\
\text { (kg) u. } \\
\text { Gesch- } \\
\text { lecht }\end{array}$} & \multirow{2}{*}{$\begin{array}{l}\text { Zeit ror } \\
\text { od. nach d. } \\
\text { Operation } \\
\text { (Min.) }\end{array}$} & \multicolumn{2}{|c|}{$\begin{array}{l}\text { Hïmoglobin } \\
\text { d. art. Blutes }\end{array}$} & \multicolumn{2}{|c|}{$\begin{array}{l}\text { Serumeiweiss } \\
\text { d. art. Blutes }\end{array}$} & \multirow{2}{*}{$\begin{array}{c}\begin{array}{c}\text { Serum- } \\
\mathrm{NaCl} \mathrm{d.} \\
\text { art. Blutes }\end{array} \\
\mathrm{g} / \mathrm{dl}\end{array}$} \\
\hline & & & $\mathrm{g} / \mathrm{dl}$ & $\begin{array}{l}\text { Differenz } \\
\text { in } \%\end{array}$ & $\%$ & $\begin{array}{l}\text { Differenz } \\
\text { in } \%\end{array}$ & \\
\hline 1 & 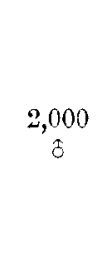 & $\begin{array}{cr}\text { Vor } & \\
\text { Nach } & 1 \\
, & 5 \\
" & 10 \\
" & 20 \\
" & 30 \\
" & 60 \\
\Rightarrow & 90 \\
" & 120\end{array}$ & $\begin{array}{l}14,52 \\
15,36 \\
15,22 \\
14,80 \\
14,52 \\
14,98 \\
14,28 \\
14,09 \\
13,94\end{array}$ & $\begin{array}{l}+5,8 \\
+4,8 \\
+1,9 \\
\pm 0 \\
-1,0 \\
-1,7 \\
-3,0 \\
-4,0\end{array}$ & $\begin{array}{l}6,379 \\
6,660 \\
6,445 \\
6,422 \\
6,336 \\
6,271 \\
6,120 \\
6,120 \\
6,055\end{array}$ & $\begin{array}{r}+4,4 \\
+1,0 \\
+0,6 \\
-0,7 \\
-1,7 \\
-4,1 \\
-4,1 \\
-5,1\end{array}$ & $\begin{array}{l}0,540 \\
0,545 \\
0,547 \\
0,545 \\
0,543 \\
0,546 \\
0,547 \\
0,547 \\
0,548\end{array}$ \\
\hline 2 & $\begin{array}{c}1,950 \\
\vdots\end{array}$ & $\begin{array}{cr}\text { Vor } & \\
\text { Nach } & 1 \\
" & 5 \\
" & 10 \\
" & 20 \\
" & 30 \\
" & 60 \\
" & 90 \\
" & 120\end{array}$ & $\begin{array}{l}13,08 \\
13,79 \\
13,50 \\
13,36 \\
13,22 \\
12,80 \\
12,66 \\
12,52 \\
12,38\end{array}$ & $\begin{array}{r}+5,4 \\
+3,2 \\
+2,1 \\
+1,1 \\
-2,1 \\
-3,2 \\
-4,3 \\
-5,4\end{array}$ & $\begin{array}{l}5,379 \\
5,575 \\
5,531 \\
5,466 \\
5,401 \\
5,248 \\
5,161 \\
5,117 \\
5,074\end{array}$ & $\begin{array}{r}+3,6 \\
+2,8 \\
+1,6 \\
+0,4 \\
-2,4 \\
-4,1 \\
-4,9 \\
-5,7\end{array}$ & $\begin{array}{l}0,620 \\
0,620 \\
0,618 \\
0,623 \\
0,623 \\
0,626 \\
0,629 \\
0,629 \\
0,631\end{array}$ \\
\hline 3 & $\begin{array}{c}2,200 \\
q\end{array}$ & $\begin{array}{cr}\text { Vor } & \\
\text { Nach } & 1 \\
\Rightarrow & 5 \\
" & 10 \\
" & 20 \\
" & 30 \\
" & 60 \\
" & 90 \\
" & 120\end{array}$ & $\begin{array}{l}14,52 \\
15,36 \\
15,08 \\
14,94 \\
14,52 \\
14,38 \\
14,24 \\
14,118 \\
13,64\end{array}$ & $\begin{array}{r}+5,8 \\
+3,9 \\
+2,9 \\
\pm 0 \\
-1,0 \\
-1,9 \\
-3,0 \\
-6,1\end{array}$ & $\begin{array}{l}5,989 \\
6,164 \\
6,098 \\
5,967 \\
5,946 \\
5,942 \\
5,858 \\
5,706 \\
5,553\end{array}$ & $\begin{array}{r}+2,9 \\
+1,8 \\
-0,4 \\
-0,7 \\
-1,5 \\
-2,2 \\
-4,7 \\
-7,3\end{array}$ & $\begin{array}{l}0,590 \\
0,595 \\
0,595 \\
0,610 \\
0,612 \\
0,615 \\
0,615 \\
0,617 \\
0,620\end{array}$ \\
\hline
\end{tabular}




\begin{tabular}{|c|c|c|c|c|c|c|c|}
\hline \multirow{2}{*}{ Nr. } & \multirow{2}{*}{$\begin{array}{c}\text { Körper- } \\
\text { gewicht } \\
\text { (kg) u. } \\
\text { Gesch- } \\
\text { lecht }\end{array}$} & \multirow{2}{*}{$\begin{array}{l}\text { Zeit vor } \\
\text { od. nach d. } \\
\text { Operation } \\
\text { (Min.) }\end{array}$} & \multicolumn{2}{|c|}{$\begin{array}{l}\text { Hämoglobin } \\
\text { d. art. Blutes }\end{array}$} & \multicolumn{2}{|c|}{$\begin{array}{l}\text { Serumeiweiss } \\
\text { d. art. Blutes }\end{array}$} & \multirow{2}{*}{$\begin{array}{l}\begin{array}{c}\text { Serum- } \\
\text { NaCl d. } \\
\text { art. Blutes }\end{array} \\
\text { g/dl }\end{array}$} \\
\hline & & & $\mathrm{g} / \mathrm{dl}$ & $\begin{array}{l}\text { Differenz } \\
\text { in } \%\end{array}$ & $\%$ & $\begin{array}{l}\text { Differenz } \\
\text { in } \%\end{array}$ & \\
\hline 4 & $\begin{array}{c}2,100 \\
\stackrel{9}{q}\end{array}$ & $\begin{array}{cr}\text { Vor } & \\
\text { Nach } & 1 \\
, & 5 \\
" & 10 \\
, & 20 \\
" & 30 \\
" & 60 \\
" & 90 \\
, & 120 \\
\end{array}$ & $\begin{array}{l}13,36 \\
14,09 \\
13,79 \\
13,64 \\
13,36 \\
13,08 \\
12,94 \\
12,80 \\
12,52 \\
\end{array}$ & $\begin{array}{l}+5,5 \\
+3,2 \\
+2,1 \\
\pm 0 \\
-2,1 \\
-3,1 \\
-4,2 \\
-6,3 \\
\end{array}$ & $\begin{array}{l}6,898 \\
7,135 \\
7,070 \\
7,006 \\
6,768 \\
6,660 \\
6,638 \\
6,574 \\
6,422 \\
\end{array}$ & $\begin{array}{l}+3,4 \\
+2,5 \\
+1,6 \\
-1,9 \\
-3,5 \\
-3,8 \\
-4,7 \\
-6,9 \\
\end{array}$ & $\begin{array}{l}0,565 \\
0,570 \\
0,568 \\
0,568 \\
0,569 \\
0,573 \\
0,575 \\
0,579 \\
0,583\end{array}$ \\
\hline 5 & $\begin{array}{c}2,000 \\
+P\end{array}$ & $\begin{array}{cr}\text { Vor } & \\
\text { Nach } & 1 \\
\Rightarrow & 5 \\
" & 10 \\
" & 20 \\
" & 30 \\
" & 60 \\
" & 90 \\
" & 120 \\
\end{array}$ & $\begin{array}{l}12,24 \\
12,94 \\
12,80 \\
12,52 \\
12,38 \\
11,96 \\
11,82 \\
11,66 \\
11,36\end{array}$ & $\begin{array}{l}+5,7 \\
+4,6 \\
+2,3 \\
+1,1 \\
-2,3 \\
-3,4 \\
-4,7 \\
-7,2\end{array}$ & $\begin{array}{l}5,858 \\
6,033 \\
6,011 \\
5,967 \\
5,815 \\
5,684 \\
5,640 \\
5,553 \\
5,466\end{array}$ & $\begin{array}{l}+3,0 \\
+2,6 \\
+1,9 \\
-0,8 \\
-3,0 \\
-3,7 \\
-5,2 \\
-6,7\end{array}$ & $\begin{array}{l}0,665 \\
0,665 \\
0,667 \\
0,664 \\
0,664 \\
0,662 \\
0,675 \\
0,677 \\
0,679\end{array}$ \\
\hline 6 & $\underset{\substack{2,500 \\
\delta}}{2,5}$ & $\begin{array}{cr}\text { Vor } & \\
\text { Nach } & 1 \\
" & 5 \\
" & 10 \\
" & 20 \\
" & 30 \\
" & 60 \\
" & 90 \\
" & 120\end{array}$ & $\begin{array}{l}13,64 \\
14,38 \\
14,24 \\
14,09 \\
13,79 \\
13,50 \\
13,36 \\
13,08 \\
12,80\end{array}$ & $\begin{array}{l}+5,4 \\
+4,4 \\
+3,3 \\
+1,1 \\
-1,0 \\
-2,1 \\
-4,1 \\
-6,2\end{array}$ & $\begin{array}{l}5,793 \\
5,902 \\
5,880 \\
5,837 \\
5,684 \\
5,640 \\
5,619 \\
5,581 \\
5,488\end{array}$ & $\begin{array}{l}+3,6 \\
+1,5 \\
+0,8 \\
-1,9 \\
-2,6 \\
-3,0 \\
-4,5 \\
-5,3\end{array}$ & $\begin{array}{l}0,514 \\
0,523 \\
0,523 \\
0,520 \\
0,521 \\
0,512 \\
0,520 \\
0,526 \\
0,527\end{array}$ \\
\hline 7 & $\begin{array}{c}2,150 \\
\hat{\delta}\end{array}$ & $\begin{array}{cr}\text { Vor } & \\
\text { Nach } & 1 \\
" & 5 \\
" & 10 \\
" & 20 \\
" & 30 \\
" & 60 \\
" & 90 \\
" & 120\end{array}$ & $\begin{array}{l}12,52 \\
13,22 \\
13,08 \\
12,80 \\
12,66 \\
12,52 \\
11,96 \\
11,66 \\
11,66\end{array}$ & $\begin{array}{l}+5,6 \\
+4,5 \\
+2,2 \\
+1,1 \\
\pm 0 \\
-4,5 \\
-6,9 \\
-6,9\end{array}$ & $\begin{array}{l}5,837 \\
5,989 \\
5,967 \\
5,924 \\
5,858 \\
5,706 \\
5,531 \\
5,379 \\
5,422\end{array}$ & $\begin{array}{l}+2,6 \\
+2,2 \\
+1,5 \\
+0,4 \\
-2,2 \\
-5,2 \\
-7,8 \\
-7,1\end{array}$ & $\begin{array}{l}0,617 \\
0,619 \\
0,621 \\
0.621 \\
0,615 \\
0,615 \\
0,625 \\
0,627 \\
0,631\end{array}$ \\
\hline
\end{tabular}

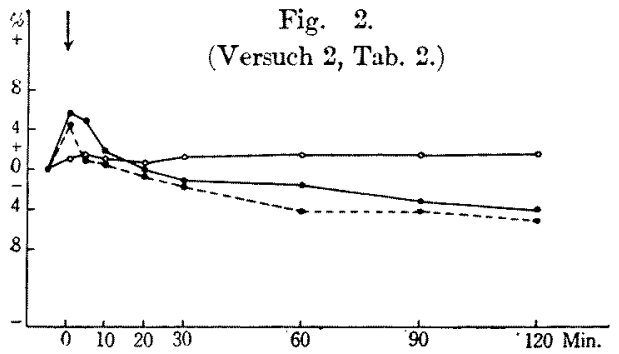

Kurz, künstlicher Paraffinothorax ruft sofort vorübergehende $\mathrm{Zu}$ nahme des Hämoglobins und Serumeiweisses hervor, und der Grad des ersteren ist stärker als der des letzteren; das erstere - Hümoglobin. $\multimap$ Serum- $\mathrm{NaCl}$. kehrt während innerhalb $\downarrow-$ Paraffininjektion in die rechte Pleurahöhle. 10-20 Minuten nach der 
Beschränkung der Atemfläche und das letztere noch früher zum Anfangswert zurück. Und das Serumkochsalz nimmt nach der Injektion des Paraffins mehr oder weniger zu, der Grad hierbei ist jedoch sehr geringfügig.

(b) Versuch an Urankaninchen.

Nach der schon besprochenen Methode habe ich 5 Kaninchen Uranylnitrat injiziert und nach Injektion von Paraffinum fluidum an solchen mit

Tabelle 3.

Veränderung der Blutkonzentration durch Anlegen des Paraffinothorax bei Urankaninchen.

\begin{tabular}{|c|c|c|c|c|c|c|c|}
\hline \multirow{2}{*}{ Nr. } & \multirow{2}{*}{$\begin{array}{l}\text { Körper- } \\
\text { gewicht } \\
\text { (kg) u. } \\
\text { Gesch- } \\
\text { lecht }\end{array}$} & \multirow{2}{*}{$\begin{array}{l}\text { Zeit vor } \\
\text { od. nach d. } \\
\text { Operation } \\
\text { (Min.) }\end{array}$} & \multicolumn{2}{|c|}{$\begin{array}{l}\text { Hämoglobin } \\
\text { d. art. Blutes }\end{array}$} & \multicolumn{2}{|c|}{$\begin{array}{l}\text { Serumeiweiss } \\
\text { d. art. Blutes }\end{array}$} & \multirow{2}{*}{$\frac{\begin{array}{c}\text { Serum- } \\
\text { NaCl d. } \\
\text { art. Blutes }\end{array}}{\mathrm{g} / \mathrm{dl}}$} \\
\hline & & & $\mathrm{g} / \mathrm{dl}$ & $\begin{array}{c}\text { Differenz } \\
\text { in } \%\end{array}$ & $\%$ & $\begin{array}{c}\text { Differenz } \\
\text { in } \%\end{array}$ & \\
\hline 1 & $\begin{array}{c}2,100 \\
3\end{array}$ & $\begin{array}{cr}\text { Vor } & \\
\text { Nach } & 1 \\
" & 5 \\
" & 10 \\
" & 20 \\
" & 30 \\
" & 60 \\
" & 90 \\
" & 120\end{array}$ & $\begin{array}{l}10,66 \\
11,36 \\
11,22 \\
10,94 \\
10,80 \\
10,76 \\
10,52 \\
10,38 \\
10,24\end{array}$ & $\begin{array}{r}+6,6 \\
+5,3 \\
+2,9 \\
+1,3 \\
+0,9 \\
-1,3 \\
-2,6 \\
-3,9\end{array}$ & $\begin{array}{l}6,055 \\
6,120 \\
6,098 \\
6,076 \\
6,055 \\
5,967 \\
5,924 \\
5,858 \\
5,771\end{array}$ & $\begin{array}{l}+1,1 \\
+0,7 \\
+0,3 \\
+0 \\
-1,5 \\
-2,2 \\
-3,3 \\
-4,7\end{array}$ & $\begin{array}{l}0,550 \\
0,557 \\
0,553 \\
0,554 \\
0,554 \\
0,556 \\
0,558 \\
0,560 \\
0,560\end{array}$ \\
\hline 2 & $\begin{array}{c}2,650 \\
\hat{\delta}\end{array}$ & $\begin{array}{cr}\text { Vor } & \\
\text { Nach } & 1 \\
" & 5 \\
" & 10 \\
" & 20 \\
" & 30 \\
" & 60 \\
" & 90 \\
" & 120\end{array}$ & $\begin{array}{l}12,52 \\
13,22 \\
13,08 \\
12,80 \\
12,80 \\
12,66 \\
12,24 \\
12,10 \\
12,10\end{array}$ & $\begin{array}{r}+5,6 \\
+4,5 \\
+2,2 \\
+2,2 \\
+1,1 \\
-2,2 \\
-3,4 \\
-3,4\end{array}$ & $\begin{array}{l}5,967 \\
6,055 \\
6,033 \\
6,011 \\
6,011 \\
5,967 \\
5,814 \\
5,706 \\
5,684\end{array}$ & $\begin{array}{l}+1,5 \\
+1,1 \\
+0,7 \\
+0,7 \\
+0 \\
-2,6 \\
-4,4 \\
-4,7\end{array}$ & $\begin{array}{l}0,580 \\
0,585 \\
0,580 \\
0,580 \\
0,580 \\
0,583 \\
0,586 \\
0,588 \\
0,587\end{array}$ \\
\hline 3 & $\begin{array}{c}2,050 \\
\hat{\delta}\end{array}$ & $\begin{array}{cr}\text { Vor } & \\
\text { Nach } & 1 \\
" & 5 \\
" & 10 \\
" & 20 \\
" & 30 \\
" & 60 \\
" & 90 \\
" & 120 \\
\end{array}$ & $\begin{array}{l}14,52 \\
15,36 \\
15,22 \\
15,08 \\
14,80 \\
14,66 \\
14,09 \\
14,09 \\
13,79 \\
\end{array}$ & $\begin{array}{r}+5,5 \\
+4,8 \\
+2,9 \\
+1,9 \\
+1,0 \\
-3,9 \\
-3,9 \\
-5,9 \\
\end{array}$ & $\begin{array}{l}5,861 \\
5,967 \\
5,924 \\
5,902 \\
5,861 \\
5,861 \\
5,597 \\
5,488 \\
5,466 \\
\end{array}$ & $\begin{array}{l}+1,8 \\
+1,1 \\
+0,7 \\
\pm 0 \\
\pm 0 \\
-4,5 \\
-4,7 \\
-6,7\end{array}$ & $\begin{array}{l}0,596 \\
0,601 \\
0,600 \\
0,605 \\
0,610 \\
0,610 \\
0,607 \\
0,610 \\
0,615 \\
\end{array}$ \\
\hline 4 & $\begin{array}{c}2,030 \\
3\end{array}$ & $\begin{array}{cr}\text { Vor } & \\
\text { Nach } & 1 \\
" & 5 \\
" & 10 \\
" & 20 \\
" & 30 \\
" & 60 \\
" & 90 \\
" & 120\end{array}$ & $\begin{array}{l}11,66 \\
12,38 \\
12,24 \\
12,24 \\
11,96 \\
11,81 \\
11,36 \\
11,22 \\
10,94\end{array}$ & $\begin{array}{r}+6,2 \\
+5,0 \\
+5,0 \\
+2,6 \\
+1,3 \\
-2,6 \\
-3,8 \\
-6,2\end{array}$ & $\begin{array}{l}5,924 \\
5,989 \\
5,967 \\
5,945 \\
5,945 \\
5,924 \\
5,749 \\
5,684 \\
5,581\end{array}$ & $\begin{array}{l}+1,1 \\
+0,7 \\
+0,4 \\
+0,4 \\
\pm 0 \\
-3,0 \\
-4,1 \\
-6,6\end{array}$ & $\begin{array}{l}0,541 \\
0,545 \\
0,547 \\
0,545 \\
0,545 \\
0,546 \\
0,549 \\
0,549 \\
0,553\end{array}$ \\
\hline
\end{tabular}




\begin{tabular}{|c|c|c|c|c|c|c|c|}
\hline \multirow{2}{*}{ Nr. } & \multirow{2}{*}{$\begin{array}{l}\text { Körper- } \\
\text { gewicht } \\
\text { (kg) u. } \\
\text { Gesch- } \\
\text { lecht }\end{array}$} & \multirow{2}{*}{$\begin{array}{l}\text { Zeit vor } \\
\text { od, nach d. } \\
\text { Operation } \\
\text { (Min.) }\end{array}$} & \multicolumn{2}{|c|}{$\begin{array}{l}\text { Hämoglobin } \\
\text { d. art. Blutes }\end{array}$} & \multicolumn{2}{|c|}{$\begin{array}{l}\text { Serumeiweiss } \\
\text { d. art. Blutes }\end{array}$} & \multirow{2}{*}{$\frac{\begin{array}{c}\text { Serum- } \\
\text { NaCl d. } \\
\text { art. Blutes }\end{array}}{\mathrm{g} / \mathrm{dl}}$} \\
\hline & & & $\mathrm{g} / \mathrm{dl}$ & $\begin{array}{c}\text { Differenz } \\
\text { in } \%\end{array}$ & $\%$ & $\begin{array}{c}\text { Differenz } \\
\text { in } \%\end{array}$ & \\
\hline 5 & $\begin{array}{c}1,870 \\
\hat{6}\end{array}$ & $\begin{array}{cr}\text { Vor } & \\
\text { Nach } & 1 \\
, & 5 \\
" & 10 \\
" & 20 \\
" & 30 \\
" & 60 \\
" & 90 \\
" & 120\end{array}$ & $\begin{array}{l}13,36 \\
14,09 \\
13,94 \\
13,64 \\
13,50 \\
13,08 \\
12,94 \\
12,80 \\
12,52\end{array}$ & $\begin{array}{l}+5,5 \\
+4,3 \\
+2,1 \\
+1,0 \\
-2,1 \\
-3,1 \\
-4,2 \\
-6,2\end{array}$ & $\begin{array}{l}6,055 \\
6,228 \\
6,098 \\
6,076 \\
6,076 \\
5,837 \\
5,793 \\
5,771 \\
5,662\end{array}$ & $\begin{array}{r}+2,8 \\
+0,7 \\
+0,3 \\
+0,3 \\
-3,6 \\
-4,3 \\
-4,7 \\
-6,5\end{array}$ & $\begin{array}{l}0,572 \\
0,579 \\
0,579 \\
0,578 \\
0,576 \\
0,580 \\
0,582 \\
0,585 \\
0,589\end{array}$ \\
\hline
\end{tabular}

deutlichen Symptomen der Vergiftung das Hämoglobin-, Serumeiweissund Serumkochsalzgehalt des Bluts zeitlich beobachtet (Tab. 3).

Bei der Übersicht der Tabelle kann man finden, dass die Veränderungen des Hämoglobin-, des Serumeiweiss- und des Serumkochsalzgehalts fast die gleiche Neigung haben, wenn sie auch quantitativ mehr oder weniger verschieden sind. Kurz, die Befunde an Urankaninchen sind denen an gesunden Kaninchen ähnlich, die Zunahme des Hämoglobins bei den ersteren aber ist stïrker als die bei den letzteren und die des Serumeiweisses ist im Gegenteil geringer. Das vermehrte Hïmoglobin kommt meist auch 30 Minuten noch nicht zum Anfangswert zurück, aber das ein wenig vermehrte Serumeiweiss kehrt während 10-20 Minuten nach und nach zum Anfangswert zurück.

\section{(c) Versuch an Cantharidinkaninchen.}

Lege artis injizierte ich 5 Kaninchen Cantharidin, und als Vergiftungssymptome deutlich wurden, entnahm ich das Blut; alles weitere ist ganz gleich wie bei (b). Die Resultate zeigen Tab. 4.

Aus der Tabelle geht hervor, dass bei den mit Paraffin injizierten Cantharidinkaninchen die Veränderungen des Hämoglobins, Serumeiweisses und Serumkochsalzes denen bei Urankaninchen ähnlich sind, nur dass die Zunahme des Hämoglobins bei jenen stärker als bei diesen, die Zunahme des Serumeiweisses aber bei jenen schwächer als bei Urankaninchen ist. Das Hämoglobin kommt meist noch nicht nach 30 Minuten, sondern erst nach 60 Minuten zum Anfangswert zurück. Das Serumeiweiss kehrt im allgemeinen nach 10-20 Minuten zum Anfangswert zurück. 
Tabelle 4.

Verïnderung der Blutkonzentration durch Anlegen des Paraffinothorax bei Kantharidinkaninchen.

\begin{tabular}{|c|c|c|c|c|c|c|c|}
\hline \multirow{2}{*}{ Nr. } & \multirow{2}{*}{$\begin{array}{l}\text { Körper- } \\
\text { gewicht } \\
\text { (kg) u. } \\
\text { Gesch- } \\
\text { lecht }\end{array}$} & \multirow{2}{*}{$\begin{array}{c}\text { Zeit der } \\
\text { Blut- } \\
\text { entnahme } \\
\text { (Min.) }\end{array}$} & \multicolumn{2}{|c|}{$\begin{array}{l}\text { Hümoglobin } \\
\text { d. art. Blutes }\end{array}$} & \multicolumn{2}{|c|}{$\begin{array}{l}\text { Serumeiweiss } \\
\text { d. art. Blutes }\end{array}$} & \multirow{2}{*}{$\begin{array}{c}\begin{array}{c}\text { Serum- } \\
\mathrm{NaCl} \mathrm{d} . \\
\text { art. Blutes }\end{array} \\
\mathrm{g} / \mathrm{dl}\end{array}$} \\
\hline & & & $\mathrm{g} / \mathrm{dl}$ & $\begin{array}{c}\text { Differenz } \\
\text { in } \%\end{array}$ & $\%$ & $\begin{array}{c}\text { Differenz } \\
\text { in } \%\end{array}$ & \\
\hline 1 & $\begin{array}{c}2,100 \\
\hat{\delta}\end{array}$ & $\begin{array}{cr}\text { Vor } & \\
\text { Nach } & 1 \\
" & 5 \\
" & 10 \\
" & 20 \\
" & 30 \\
" & 60 \\
" & 90 \\
" & 120\end{array}$ & $\begin{array}{l}12,24 \\
13,36 \\
13,08 \\
12,94 \\
12,52 \\
12,38 \\
12,24 \\
11,96 \\
11,68\end{array}$ & $\begin{array}{l}+9,2 \\
+6,9 \\
+5,7 \\
+2,3 \\
+1,1 \\
+0 \\
-2,3 \\
-4,6\end{array}$ & $\begin{array}{l}5,684 \\
5,771 \\
5,728 \\
5,706 \\
5,684 \\
5,597 \\
5,575 \\
5,422 \\
5,401\end{array}$ & $\begin{array}{l}+1,5 \\
+0,7 \\
+0,4 \\
\pm 0 \\
-1,5 \\
-1,9 \\
-4,6 \\
-5,0\end{array}$ & $\begin{array}{l}0,497 \\
0,502 \\
0,502 \\
0,503 \\
0,503 \\
0,506 \\
0,505 \\
0,510 \\
0,513\end{array}$ \\
\hline 2 & $\begin{array}{c}1,970 \\
3\end{array}$ & $\begin{array}{cr}\text { Vor } & \\
\text { Nach } & 1 \\
" & 5 \\
" & 10 \\
" & 20 \\
" & 30 \\
, & 60 \\
" & 90 \\
" & 120\end{array}$ & $\begin{array}{l}12,80 \\
13,94 \\
13,64 \\
13,36 \\
13,22 \\
13,08 \\
12,80 \\
12,52 \\
12,24\end{array}$ & $\begin{array}{l}+8,9 \\
+6,6 \\
+4,4 \\
+3,3 \\
+2,2 \\
\pm 0 \\
-2,2 \\
-4,4\end{array}$ & $\begin{array}{l}5,749 \\
5,815 \\
5,771 \\
5,771 \\
5,749 \\
5,728 \\
5,706 \\
5,575 \\
5,488\end{array}$ & $\begin{array}{l}+1,1 \\
+0,4 \\
+0,4 \\
\pm 0 \\
-0,4 \\
-0,7 \\
-3,0 \\
-4,5\end{array}$ & $\begin{array}{l}0,521 \\
0,526 \\
0,526 \\
0,525 \\
0,524 \\
0,524 \\
0,525 \\
0,527 \\
0,528\end{array}$ \\
\hline 3 & $\begin{array}{c}2,300 \\
?\end{array}$ & $\begin{array}{cr}\text { Vor } & \\
\text { Nach } & 1 \\
" & 5 \\
" & 10 \\
" & 20 \\
" & 30 \\
" & 60 \\
" & 120\end{array}$ & $\begin{array}{l}13,64 \\
14,66 \\
14,52 \\
14,09 \\
13,94 \\
13,64 \\
13,22 \\
13,22\end{array}$ & $\begin{array}{l}+7,5 \\
+6,5 \\
+3,3 \\
+2,2 \\
\pm 0 \\
-3,1 \\
-4,1\end{array}$ & $\begin{array}{l}5,902 \\
5,967 \\
5,946 \\
5,924 \\
5,924 \\
5,837 \\
5,771 \\
5,640\end{array}$ & $\begin{array}{l}+1,1 \\
+0,7 \\
+0,4 \\
+0,4 \\
-1,1 \\
-2,2 \\
-3,7\end{array}$ & $\begin{array}{l}0,513 \\
0,517 \\
0,516 \\
0,516 \\
0,516 \\
0,517 \\
0,518 \\
0,519\end{array}$ \\
\hline 4 & $\begin{array}{c}2,170 \\
3\end{array}$ & $\begin{array}{cr}\text { Vor } & \\
\text { Nach } & 1 \\
, " & 5 \\
" & 10 \\
" & 20 \\
" & 30 \\
" & 60 \\
" & 90 \\
" & 120\end{array}$ & $\begin{array}{l}12,94 \\
13,79 \\
13,64 \\
13,50 \\
13,36 \\
13,08 \\
12,94 \\
12,52 \\
12,24\end{array}$ & $\begin{array}{l}+6,6 \\
+5,4 \\
+4,3 \\
+3,2 \\
+1,1 \\
+0 \\
-8,2 \\
-4,6\end{array}$ & $\begin{array}{l}5,728 \\
5,815 \\
5,771 \\
5,749 \\
5,749 \\
5,728 \\
5,706 \\
5,510 \\
5,444\end{array}$ & $\begin{array}{l}+1,5 \\
+0,8 \\
+0,4 \\
+0,4 \\
\pm 0 \\
-0,4 \\
-3,8 \\
-5,0\end{array}$ & $\begin{array}{l}0,527 \\
0,529 \\
0,528 \\
0,527 \\
0,527 \\
0,528 \\
0,529 \\
0,533 \\
0,539\end{array}$ \\
\hline 5 & $\begin{array}{c}2,070 \\
?+\end{array}$ & $\begin{array}{cr}\text { Vor } & \\
\text { Nach } & 1 \\
& 1 \\
" & 10 \\
" & 20 \\
" & 30 \\
" & 60 \\
" & 90 \\
" & 120\end{array}$ & $\begin{array}{l}12,52 \\
13,36 \\
13,22 \\
12,08 \\
12,80 \\
12,66 \\
12,38 \\
12,24 \\
11,81\end{array}$ & $\begin{array}{l}+6,7 \\
+5,6 \\
+4,5 \\
+2,2 \\
+1,1 \\
-1,1 \\
-2,2 \\
-5,6\end{array}$ & $\begin{array}{l}5,488 \\
5,553 \\
5,531 \\
5,510 \\
5,466 \\
5,466 \\
5,401 \\
5,335 \\
5,139\end{array}$ & $\begin{array}{l}+1,2 \\
+0,8 \\
+0,4 \\
-0,4 \\
-0,4 \\
-1,6 \\
-2,8 \\
-6,4\end{array}$ & $\begin{array}{l}0,546 \\
0,550 \\
0,549 \\
0,548 \\
0,547 \\
0,549 \\
0,551 \\
0,553 \\
0,556\end{array}$ \\
\hline
\end{tabular}


2. Bei der Ausschaltung der einseitigen Lunge.

(a) Versuch im gesunden Zustand.

Ich habe eine Kanüle in den rechten Hauptbronchus der Kaninchen eingeführt und die linke Lunge aus der Atmung ausgeschaltet und dann den Hämoglobin-, den Serumeiweiss- und den Serumkochsalzgehalt nach je

Tabelle 5 .

Veränderung der Blutkonzentration durch Ausschaltung einer Lunge bei normalen Kaninchen.

\begin{tabular}{|c|c|c|c|c|c|c|c|}
\hline \multirow{2}{*}{ Nr. } & \multirow{2}{*}{$\begin{array}{l}\text { Körper- } \\
\text { gewicht } \\
\text { (kg) u. } \\
\text { Gesch- } \\
\text { lecht }\end{array}$} & \multirow{2}{*}{$\begin{array}{c}\text { Zeit der } \\
\text { Blut- } \\
\text { entnahme } \\
\text { (Min.) }\end{array}$} & \multicolumn{2}{|c|}{$\begin{array}{l}\text { Hümoglobin } \\
\text { d. art. Blutes }\end{array}$} & \multicolumn{2}{|c|}{$\begin{array}{l}\text { Serumeiweiss } \\
\text { d. art. Blutes }\end{array}$} & \multirow{2}{*}{$\begin{array}{c}\begin{array}{c}\text { Serum- } \\
\text { NaCl d. } \\
\text { art. Blutes }\end{array} \\
\text { g/dl }\end{array}$} \\
\hline & & & $\mathrm{g} / \mathrm{d} \mathrm{l}$ & $\begin{array}{l}\text { Differenz } \\
\text { in } \%\end{array}$ & $\%$ & $\begin{array}{l}\text { Differenz } \\
\text { in \% }\end{array}$ & \\
\hline 1 & $\begin{array}{c}2,150 \\
+\end{array}$ & $\begin{array}{cr}\text { Vor } & \\
\text { Nach } & 1 \\
, & 5 \\
" & 10 \\
" & 20 \\
" & 30 \\
" & 60 \\
" & 90 \\
" & 120\end{array}$ & $\begin{array}{l}13,64 \\
14,38 \\
14,24 \\
13,94 \\
13,50 \\
13,36 \\
13,08 \\
12,80 \\
12,80\end{array}$ & $\begin{array}{r}+5,4 \\
+4,4 \\
+2,2 \\
-1,0 \\
-2,1 \\
-4,1 \\
-6,2 \\
-6,2\end{array}$ & $\begin{array}{l}5,335 \\
5,488 \\
5,444 \\
5,379 \\
5,204 \\
5,161 \\
5,074 \\
4,943 \\
4,943\end{array}$ & $\begin{array}{r}+2,9 \\
+2,0 \\
+0,8 \\
-2,5 \\
-3,3 \\
-4,9 \\
-7,3 \\
-7,3\end{array}$ & $\begin{array}{l}0,513 \\
0,514 \\
0,514 \\
0,513 \\
0,513 \\
0,515 \\
0,517 \\
0,520 \\
0,520\end{array}$ \\
\hline 2 & $\begin{array}{c}2,300 \\
\hat{0}\end{array}$ & $\begin{array}{cr}\text { Vor } & \\
\text { Nach } & \mathbf{1} \\
\Rightarrow & 5 \\
" & 10 \\
" & 20 \\
" & 30 \\
" & 60 \\
" & 90 \\
" & 120\end{array}$ & $\begin{array}{l}10,52 \\
11,08 \\
10,94 \\
10,80 \\
10,52 \\
10,38 \\
10,24 \\
10,10 \\
10,10\end{array}$ & $\begin{array}{l}+5,3 \\
+4,0 \\
+2,7 \\
\pm 0 \\
-1,3 \\
-2,7 \\
-4,0 \\
-4,0\end{array}$ & $\begin{array}{l}6,228 \\
6,379 \\
6,293 \\
6,228 \\
6,163 \\
6,120 \\
6,011 \\
5,946 \\
5,924\end{array}$ & $\begin{array}{l}+2,4 \\
+1,0 \\
\pm 0 \\
-1,4 \\
-1,7 \\
-3,5 \\
-4,5 \\
-4,9\end{array}$ & $\begin{array}{l}0,556 \\
0,567 \\
0,563 \\
0,559 \\
0,556 \\
0,556 \\
0,559 \\
0,568 \\
0,569\end{array}$ \\
\hline 8 & $\begin{array}{c}2,100 \\
\$\end{array}$ & $\begin{array}{cr}\text { Vor } & \\
\text { Nach } & 1 \\
" & 5 \\
" & 10 \\
" & 20 \\
" & 30 \\
" & 60 \\
" & 90 \\
" & 120\end{array}$ & $\begin{array}{l}11,66 \\
12,24 \\
12,10 \\
11,96 \\
11,36 \\
11,22 \\
11,08 \\
10,94 \\
10,94\end{array}$ & $\begin{array}{l}+5,0 \\
+3,8 \\
+2,6 \\
-2,6 \\
-3,8 \\
-5,0 \\
-6,2 \\
-6,2\end{array}$ & $\begin{array}{l}5,619 \\
5,815 \\
5,640 \\
5,619 \\
5,401 \\
5,379 \\
5,313 \\
5,248 \\
5,248\end{array}$ & $\begin{array}{l}+3,5 \\
+0,4 \\
\pm 0 \\
-3,9 \\
-4,3 \\
-5,4 \\
-6,6 \\
-6,6\end{array}$ & $\begin{array}{l}0,526 \\
0,529 \\
0,528 \\
0,528 \\
0,529 \\
0,530 \\
0,530 \\
0,533 \\
0,533\end{array}$ \\
\hline 4 & $\begin{array}{c}1,950 \\
3\end{array}$ & $\begin{array}{cr}\text { Vor } & \\
\text { Nach } & 1 \\
" & 5 \\
" & 10 \\
" & 20 \\
" & 30 \\
" & 60 \\
" & 90 \\
" & 120\end{array}$ & $\begin{array}{l}12,80 \\
13,50 \\
13,36 \\
13,22 \\
12,94 \\
12,80 \\
12,66 \\
12,24 \\
12,10\end{array}$ & $\begin{array}{l}+5,5 \\
+4,4 \\
+3,3 \\
+1,1 \\
\pm 0 \\
-1,1 \\
-4,4 \\
-5,5\end{array}$ & $\begin{array}{l}5,728 \\
5,837 \\
5,793 \\
5,749 \\
5,597 \\
5,531 \\
5,466 \\
5,444 \\
5,379\end{array}$ & $\begin{array}{r}+1,9 \\
+1,1 \\
+0,4 \\
-2,3 \\
-3,4 \\
-4,6 \\
-5,0 \\
-6,1\end{array}$ & $\begin{array}{l}0,547 \\
0,553 \\
0,555 \\
0,556 \\
0,553 \\
0,554 \\
0,556 \\
0,559 \\
0,559\end{array}$ \\
\hline
\end{tabular}




\begin{tabular}{|c|c|c|c|c|c|c|c|}
\hline \multirow{2}{*}{ Nr. } & \multirow{2}{*}{$\begin{array}{l}\text { Körper- } \\
\text { gewicht } \\
\text { (kg) u. } \\
\text { Gesch- } \\
\text { lecht }\end{array}$} & \multirow{2}{*}{$\begin{array}{c}\text { Zeit der } \\
\text { Blut- } \\
\text { entnahme } \\
\text { (Min.) }\end{array}$} & \multicolumn{2}{|c|}{$\begin{array}{l}\text { Hämoglobin } \\
\text { d. art. Blutes }\end{array}$} & \multicolumn{2}{|c|}{$\begin{array}{l}\text { Serumeiweiss } \\
\text { d. art. Blutes }\end{array}$} & \multirow{2}{*}{$\begin{array}{c}\begin{array}{c}\text { Serum- } \\
\text { NaCl d. } \\
\text { art. Blutes }\end{array} \\
\text { g/dl }\end{array}$} \\
\hline & & & $\mathrm{g} / \mathrm{dl}$ & $\begin{array}{l}\text { Differenz } \\
\text { in } \%\end{array}$ & $\%$ & $\begin{array}{l}\text { Differenz } \\
\text { in } \%\end{array}$ & \\
\hline 5 & $\begin{array}{c}2,150 \\
\text { P }\end{array}$ & $\begin{array}{cr}\text { Vor } & \\
\text { Nach } & 1 \\
" & 5 \\
" & 10 \\
" & 20 \\
" & 30 \\
" & 60 \\
" & 90 \\
" & 120\end{array}$ & $\begin{array}{l}13,94 \\
14,66 \\
14,52 \\
14,24 \\
14,09 \\
13,64 \\
13,64 \\
13,36 \\
13,22\end{array}$ & $\begin{array}{r}+5,2 \\
+4,2 \\
+2,2 \\
+1,1 \\
-2,2 \\
-2,2 \\
-4,2 \\
-5,2\end{array}$ & $\begin{array}{l}6,033 \\
6,142 \\
6,076 \\
6,055 \\
6,055 \\
5,880 \\
5,815 \\
5,749 \\
5,706\end{array}$ & $\begin{array}{l}+1,8 \\
+0,7 \\
+0,4 \\
+0,4 \\
-2,5 \\
-3,6 \\
-4,7 \\
-5,7\end{array}$ & $\begin{array}{l}0,524 \\
0,527 \\
0,527 \\
0,524 \\
0,525 \\
0,527 \\
0,529 \\
0,532 \\
0,534\end{array}$ \\
\hline 6 & $\begin{array}{c}2,000 \\
\text { ? }\end{array}$ & $\begin{array}{cr}\text { Vor } & \\
\text { Nach } & 1 \\
" & 5 \\
" & 10 \\
" & 20 \\
" & 30 \\
" & 60 \\
" & 90 \\
" & 120\end{array}$ & $\begin{array}{l}11,96 \\
12,68 \\
12,52 \\
12,38 \\
12,24 \\
12,10 \\
11,66 \\
11,36 \\
11,08\end{array}$ & $\begin{array}{r}+6,0 \\
+4,7 \\
+3,5 \\
+2,3 \\
+1,2 \\
-2,5 \\
-5,0 \\
-7,4\end{array}$ & $\begin{array}{l}5,728 \\
5,858 \\
5,815 \\
5,793 \\
5,749 \\
5,531 \\
5,379 \\
5,292 \\
5,292\end{array}$ & $\begin{array}{l}+2,3 \\
+1,5 \\
+1,1 \\
+0,4 \\
-3,4 \\
-6,1 \\
-7,6 \\
-7,6\end{array}$ & $\begin{array}{l}0,531 \\
0,534 \\
0,532 \\
0,529 \\
0,529 \\
0,533 \\
0,536 \\
0,537 \\
0,539\end{array}$ \\
\hline 7 & $\begin{array}{c}2,230 \\
\hat{3}\end{array}$ & $\begin{array}{cr}\text { Vor } & \\
\text { Nach } & 1 \\
, & 5 \\
" & 10 \\
" & 20 \\
" & 30 \\
" & 60 \\
" & 90 \\
" & 120\end{array}$ & $\begin{array}{l}13,36 \\
14,09 \\
13,94 \\
13,79 \\
13,64 \\
13,36 \\
12,94 \\
12,80 \\
12,52\end{array}$ & $\begin{array}{l}+5,5 \\
+4,3 \\
+3,2 \\
+2,1 \\
\pm 0 \\
-3,1 \\
-4,2 \\
-6,2\end{array}$ & $\begin{array}{l}6,336 \\
6,509 \\
6,444 \\
6,379 \\
6,314 \\
6,206 \\
6,120 \\
5,989 \\
5,580\end{array}$ & $\begin{array}{l}+2,6 \\
+1,7 \\
+0,7 \\
-0,3 \\
-2,1 \\
-3,4 \\
-5,5 \\
-7,2\end{array}$ & $\begin{array}{l}0,563 \\
0,566 \\
0,567 \\
0,564 \\
0,565 \\
0,566 \\
0,569 \\
0,571 \\
0,573\end{array}$ \\
\hline
\end{tabular}

1, 5, 10, 20, 30, 60, 90 und 120 Minuten untersucht. Die Resultate sind an 7 Versuchen im grossen und ganzen ähnlich (Tab. 5).

Kurz, bei der Ausschaltung der einseitigen Lunge veründert sich auch Hämoglobin sowie Serumeiweiss qualitativ und quantitativ fast gleich wie bei künstlichem Paraffinothorax ; hierbei ist auch die Zunahme des Serumeiweisses geringfügiger als die des Hümoglobins.

\section{(b) Versuch an Urankaninchen.}

5 Versuche ausgeführt. Die Zunahme des Hümoglobingehalts ist ausgesprochener als im gesunden Zustand ; hingegen ist beim Serumeiweissgehalt ist der Grad der Zunahme bedeutend kleiner. Serumkochsalz nimmt mehr oder weniger zu. Wenn man dies mit den Fällen der Paraffininjektion vergleicht, so ist die Zunahme des Serumeiweisses hierbei verhältnismässig kleiner als die des Hämoglobins (Tab. 6). 
Tabelle 6 .

Verïnderung der Blutkonzantration durch Aussshultung einer Lunge bei Urankaninchen.

\begin{tabular}{|c|c|c|c|c|c|c|c|}
\hline \multirow{2}{*}{ Nr. } & \multirow{2}{*}{$\begin{array}{l}\text { Körper- } \\
\text { gewicht } \\
\text { (kg) u. } \\
\text { Gesch- } \\
\text { lecht }\end{array}$} & \multirow{2}{*}{$\begin{array}{l}\text { Zeit vor } \\
\text { od. nach d. } \\
\text { Operation } \\
\text { (Min.) }\end{array}$} & \multicolumn{2}{|c|}{$\begin{array}{l}\text { Ḧ̈moglobin } \\
\text { d. art. Blutes }\end{array}$} & \multicolumn{2}{|c|}{$\begin{array}{l}\text { Serumeiweiss } \\
\text { d. art. Blutes }\end{array}$} & \multirow{2}{*}{$\frac{\begin{array}{c}\text { Serum- } \\
\text { NaCl d. } \\
\text { art. Blutes }\end{array}}{\text { g/dl }}$} \\
\hline & & & $\mathrm{g} / \mathrm{dl}$ & $\begin{array}{l}\text { Differenz } \\
\text { in } \%\end{array}$ & $\%$ & $\begin{array}{l}\text { Differenz } \\
\text { in } \%\end{array}$ & \\
\hline 1 & $\underset{2,230}{3}$ & $\begin{array}{cr}\text { Vor } & \\
\text { Nach } & 1 \\
, & 5 \\
" & 10 \\
" & 20 \\
" & 30 \\
" & 60 \\
" & 90 \\
" & 120\end{array}$ & $\begin{array}{l}10,80 \\
11,51 \\
11,36 \\
11,22 \\
11,08 \\
10,80 \\
10,66 \\
10,52 \\
10,24\end{array}$ & $\begin{array}{l}+6,6 \\
+5,2 \\
+3,9 \\
+2,6 \\
\pm 0 \\
-1,3 \\
-2,6 \\
-5,2\end{array}$ & $\begin{array}{l}4,812 \\
4,856 \\
4,834 \\
4,834 \\
4,812 \\
4,765 \\
4,725 \\
4,659 \\
4,550\end{array}$ & $\begin{array}{l}+0,9 \\
+0,5 \\
+0,5 \\
\pm 0 \\
-1,0 \\
-1,8 \\
-3,2 \\
-5,4\end{array}$ & $\begin{array}{l}0,515 \\
0,521 \\
0,521 \\
0,522 \\
0,521 \\
0,519 \\
0,523 \\
0,525 \\
0,527\end{array}$ \\
\hline 2 & $\begin{array}{c}2,200 \\
?+\end{array}$ & $\begin{array}{cr}\text { Vor } & \\
\text { Nach } & 1 \\
, & 5 \\
, & 10 \\
" & 20 \\
" & 30 \\
" & 60 \\
" & 90 \\
" & 120\end{array}$ & $\begin{array}{l}9,40 \\
9,96 \\
9,82 \\
9,54 \\
9,40 \\
9,40 \\
9,26 \\
9,12 \\
8,97\end{array}$ & $\begin{array}{l}+6,0 \\
+4,5 \\
+1,5 \\
\pm 0 \\
\pm 0 \\
-1,5 \\
-3,0 \\
-4,6\end{array}$ & $\begin{array}{l}6,055 \\
6,142 \\
6,120 \\
6,098 \\
6,076 \\
6,033 \\
5,989 \\
5,815 \\
5,728\end{array}$ & $\begin{array}{r}+1,4 \\
+1,1 \\
+0,7 \\
+0,3 \\
-0,4 \\
-1,1 \\
-4,0 \\
-5,4\end{array}$ & $\begin{array}{l}0,512 \\
0,512 \\
0,515 \\
0,514 \\
0,515 \\
0,513 \\
0,512 \\
0,517 \\
0,519\end{array}$ \\
\hline 3 & $\underset{\hat{\delta}}{2,050}$ & $\begin{array}{cr}\text { Vor } & \\
\text { Nach } & 1 \\
, & 5 \\
" & 10 \\
" & 20 \\
, & 30 \\
, & 60 \\
" & 90 \\
" & 120\end{array}$ & $\begin{array}{l}12,52 \\
13,22 \\
13,08 \\
13,08 \\
12,80 \\
12,52 \\
12,38 \\
11,96 \\
11,81\end{array}$ & $\begin{array}{l}+5,6 \\
+4,5 \\
+4,5 \\
+2,2 \\
\pm 0 \\
-1,1 \\
-4,5 \\
-5,7\end{array}$ & $\begin{array}{l}5,706 \\
5,749 \\
5,749 \\
5,728 \\
5,728 \\
5,619 \\
5,575 \\
5,488 \\
5,357\end{array}$ & $\begin{array}{l}+0,8 \\
+0,8 \\
+0,4 \\
+0,4 \\
-1,5 \\
-2,3 \\
-3,8 \\
-6,1\end{array}$ & $\begin{array}{l}0,541 \\
0,548 \\
0,548 \\
0,544 \\
0,545 \\
0,541 \\
0,543 \\
0,549 \\
0,550\end{array}$ \\
\hline 4 & $\begin{array}{c}2,100 \\
?\end{array}$ & $\begin{array}{cr}\text { Vor } & \\
\text { Nach } & 1 \\
\Rightarrow & 5 \\
" & 10 \\
" & 20 \\
" & 30 \\
" & 60 \\
" & 90 \\
" & 120\end{array}$ & $\begin{array}{l}11,08 \\
11,66 \\
11,51 \\
11,36 \\
11,22 \\
11,08 \\
10,80 \\
10,66 \\
10,38\end{array}$ & $\begin{array}{l}+5,2 \\
+3,9 \\
+2,5 \\
+1,3 \\
\pm 0 \\
-2,5 \\
-3,8 \\
-6,3\end{array}$ & $\begin{array}{l}6,076 \\
6,120 \\
6,098 \\
6,098 \\
6,055 \\
5,989 \\
5,902 \\
5,815 \\
5,684\end{array}$ & $\begin{array}{r}+0,7 \\
+0,4 \\
+0,4 \\
-0,3 \\
-1,4 \\
-2,9 \\
-4,3 \\
-6,4\end{array}$ & $\begin{array}{l}0,533 \\
0,535 \\
0,529 \\
0,531 \\
0,528 \\
0,529 \\
0,533 \\
0,535 \\
0,537\end{array}$ \\
\hline 5 & $\begin{array}{c}2,150 \\
\hat{3}\end{array}$ & $\begin{array}{cr}\text { Vor } & \\
\text { Nach } & 1 \\
\Rightarrow & 5 \\
" & 10 \\
" & 20 \\
" & 30 \\
" & 60 \\
" & 90 \\
" & 120\end{array}$ & $\begin{array}{l}10,94 \\
11,51 \\
11,36 \\
11,36 \\
11,22 \\
11,08 \\
10,80 \\
10,38 \\
10,24\end{array}$ & $\begin{array}{l}+5,2 \\
+3,8 \\
+3,8 \\
+2,6 \\
+1,3 \\
-1,3 \\
-5,1 \\
-6,4\end{array}$ & $\begin{array}{l}6,011 \\
6,076 \\
6,055 \\
6,055 \\
6,033 \\
6,011 \\
5,924 \\
5,684 \\
5,619\end{array}$ & $\begin{array}{l}+1,1 \\
+0,7 \\
+0,7 \\
+0,4 \\
+0 \\
-1,5 \\
-5,4 \\
-6,5\end{array}$ & $\begin{array}{l}0,517 \\
0,517 \\
0,519 \\
0,517 \\
0,515 \\
0,516 \\
0,520 \\
0,529 \\
0,531\end{array}$ \\
\hline
\end{tabular}


(c) Versuch an Cantharidinkaninchen.

In sümmtlichen Versuchen (im ganzen 5) konnte ich im grossen und ganzen gleiche Ergebnisse erhalten (Tab. 7).

Bei Cantharidinkaninchen ist der Grad der Zunahme des Hämoglobins ansgesprochener als bei Urankaninchen, der des Serumeiweisses aber

Tabelle 7.

Verïnderung der Blutkonzentration durch Ausschaltung einer Lunge bei Kantharidinkaninchen.

\begin{tabular}{|c|c|c|c|c|c|c|c|}
\hline \multirow{2}{*}{ Nr. } & \multirow{2}{*}{$\begin{array}{l}\text { Körper- } \\
\text { gewicht } \\
\text { (kg) u. } \\
\text { Gesch- } \\
\text { lecht }\end{array}$} & \multirow{2}{*}{$\begin{array}{l}\text { Zeit ror } \\
\text { od. nach d. } \\
\text { Operation } \\
\text { (Min.) }\end{array}$} & \multicolumn{2}{|c|}{$\begin{array}{l}\text { Hiimoglobin } \\
\text { d. art. Blutes }\end{array}$} & \multicolumn{2}{|c|}{$\begin{array}{l}\text { Serumeiweiss } \\
\text { d. art. Blutes }\end{array}$} & \multirow{2}{*}{$\begin{array}{l}\begin{array}{l}\text { Serum- } \\
\text { NaCl d. }\end{array} \\
\text { art. Blutes } \\
\text { g/dl }\end{array}$} \\
\hline & & & $\mathrm{g} / \mathrm{dl}$ & $\begin{array}{c}\text { Differenz } \\
\text { in } \%\end{array}$ & $\%$ & $\begin{array}{l}\text { Differenz } \\
\text { in } \%\end{array}$ & \\
\hline 1 & $\begin{array}{c}2,120 \\
3\end{array}$ & $\begin{array}{cr}\text { Vor } & \\
\text { Nach } & 1 \\
\Rightarrow & 5 \\
" & 10 \\
" & 20 \\
" & 30 \\
" & 60 \\
" & 90 \\
" & 120\end{array}$ & $\begin{array}{l}11,08 \\
11,96 \\
11,66 \\
11,51 \\
11,51 \\
11,22 \\
10,94 \\
10,80 \\
10,52\end{array}$ & $\begin{array}{r}+7,9 \\
+5,2 \\
+3,9 \\
+3,9 \\
+1,3 \\
-1,4 \\
-2,5 \\
-5,1\end{array}$ & $\begin{array}{l}5,030 \\
5,074 \\
5,052 \\
5,052 \\
5,030 \\
4,943 \\
4,921 \\
4,856 \\
4,725\end{array}$ & $\begin{array}{l}+0,9 \\
+0,4 \\
+0,4 \\
\pm 0 \\
-1,7 \\
-2,2 \\
-3,5 \\
-6,1\end{array}$ & $\begin{array}{l}0,587 \\
0,539 \\
0,541 \\
0,589 \\
0,541 \\
0,543 \\
0,543 \\
0,546 \\
0,549\end{array}$ \\
\hline 2 & $\begin{array}{c}2,200 \\
?\end{array}$ & $\begin{array}{cr}\text { Vor } & \\
\text { Nach } & 1 \\
" & 5 \\
" & 10 \\
" & 20 \\
" & 30 \\
" & 60 \\
" & 90 \\
" & 120\end{array}$ & $\begin{array}{l}12,24 \\
13,08 \\
12,80 \\
12,80 \\
12,52 \\
12,38 \\
12,24 \\
11,96 \\
11,66\end{array}$ & $\begin{array}{r}+6,9 \\
+4,6 \\
+4,6 \\
+2,3 \\
+1,1 \\
\pm 0 \\
-2,3 \\
-4,7\end{array}$ & $\begin{array}{l}5,902 \\
5,946 \\
5,924 \\
5,924 \\
5,902 \\
5,749 \\
5,728 \\
5,684 \\
5,581\end{array}$ & $\begin{array}{l}+0,7 \\
+0,4 \\
+0,4 \\
\pm 0 \\
-2,6 \\
-2,9 \\
-3,7 \\
-6,3\end{array}$ & $\begin{array}{l}0,560 \\
0,563 \\
0,563 \\
0,561 \\
0,561 \\
0,562 \\
0,561 \\
0,565 \\
0,571\end{array}$ \\
\hline 3 & $\begin{array}{c}2,100 \\
\delta\end{array}$ & $\begin{array}{cr}\text { Vor } & \\
\text { Nach } & 1 \\
\Rightarrow & 5 \\
" & 10 \\
" & 20 \\
" & 30 \\
" & 60 \\
" & 90 \\
" & 120\end{array}$ & $\begin{array}{l}13,94 \\
14,80 \\
14,66 \\
14,52 \\
14,24 \\
13,94 \\
13,64 \\
13,64 \\
13,36\end{array}$ & $\begin{array}{l}+6,2 \\
+5,2 \\
+4,2 \\
+2,2 \\
\pm 0 \\
-2,2 \\
-2,2 \\
-4,2\end{array}$ & $\begin{array}{l}5,292 \\
5,335 \\
5,313 \\
5,292 \\
5,204 \\
5,139 \\
5,117 \\
5,117 \\
5,030\end{array}$ & $\begin{array}{l}+0,8 \\
+0,4 \\
-0 \\
-1,7 \\
-2,9 \\
-3,3 \\
-3,3 \\
-5,0\end{array}$ & $\begin{array}{l}0,550 \\
0,556 \\
0,554 \\
0,558 \\
0,554 \\
0,559 \\
0,562 \\
0,562 \\
0,566\end{array}$ \\
\hline 4 & $\begin{array}{c}2,050 \\
\frac{1}{b}\end{array}$ & $\begin{array}{cr}\text { Vor } & \\
\text { Nach } & 1 \\
, & 5 \\
" & 10 \\
" & 20 \\
" & 30 \\
" & 60 \\
" & 90 \\
" & 120\end{array}$ & $\begin{array}{l}13,36 \\
14,24 \\
14,09 \\
13,64 \\
13,64 \\
13,50 \\
13,36 \\
12,80 \\
12,66\end{array}$ & $\begin{array}{r}+6,6 \\
+5,5 \\
+2,1 \\
+2,1 \\
+1,0 \\
\pm 0 \\
-4,2 \\
-5,2\end{array}$ & $\begin{array}{l}6,941 \\
7,006 \\
6,984 \\
6,962 \\
6,962 \\
6,896 \\
6,790 \\
6,552 \\
6,552\end{array}$ & $\begin{array}{r}+0,9 \\
+0,6 \\
+-0,3 \\
-0,3 \\
-0,9 \\
-2,2 \\
-5,6 \\
-5,6\end{array}$ & $\begin{array}{l}0,532 \\
0,534 \\
0,535 \\
0,533 \\
0,533 \\
0,539 \\
0,541 \\
0,548 \\
0,550\end{array}$ \\
\hline
\end{tabular}




\begin{tabular}{|c|c|c|c|c|c|c|c|}
\hline \multirow{2}{*}{ Nr. } & \multirow{2}{*}{$\begin{array}{l}\text { Körper- } \\
\text { gewicht } \\
\text { (kg) u. } \\
\text { Gesch- } \\
\text { lecht }\end{array}$} & \multirow{2}{*}{$\begin{array}{l}\text { Zeit vor } \\
\text { od. nach d. } \\
\text { Operation } \\
\text { (Min.) }\end{array}$} & \multicolumn{2}{|c|}{$\begin{array}{l}\text { Hämoglobin } \\
\text { d. art. Blutes }\end{array}$} & \multicolumn{2}{|c|}{$\begin{array}{l}\text { Serumeiweiss } \\
\text { d. art. Blutes }\end{array}$} & \multirow{2}{*}{$\begin{array}{l}\begin{array}{c}\text { Serum- } \\
\text { NaCl d. } \\
\text { art. Blutes }\end{array} \\
\text { g/dl }\end{array}$} \\
\hline & & & $\mathrm{g} / \mathrm{dl}$ & $\begin{array}{l}\text { Differenz } \\
\text { in } \%\end{array}$ & $\%$ & $\begin{array}{l}\text { Differenz } \\
\text { in } \%\end{array}$ & \\
\hline 5 & $\begin{array}{c}1,960 \\
q\end{array}$ & $\begin{array}{cr}\text { Vor } & \\
\text { Nach } & 1 \\
, " & 5 \\
" & 10 \\
" & 20 \\
, & 30 \\
\Rightarrow & 60 \\
" & 90 \\
, & 120\end{array}$ & $\begin{array}{l}14,24 \\
15,08 \\
14,94 \\
14,80 \\
14,66 \\
14,38 \\
13,94 \\
13,94 \\
13,78\end{array}$ & $\begin{array}{r}+5,9 \\
+4,9 \\
+3,9 \\
+2,9 \\
+1,0 \\
-2,1 \\
-2,1 \\
-3,2\end{array}$ & $\begin{array}{l}5,989 \\
6,055 \\
6,033 \\
6,011 \\
6,011 \\
5,989 \\
5,815 \\
5,815 \\
5,749\end{array}$ & $\begin{array}{r}+1,1 \\
+0,7 \\
+0,4 \\
+0,4 \\
\pm 0 \\
+2,9 \\
-2,9 \\
-4,0\end{array}$ & $\begin{array}{l}0,591 \\
0,597 \\
0,593 \\
0,593 \\
0,594 \\
0,609 \\
0,610 \\
0,617 \\
0,619\end{array}$ \\
\hline
\end{tabular}

schwächer. Und ungeachtet wiederholter Blutentnahmen sinken Hämoglobin und Serumeiweiss etwas langsamer als im gesunden Zustand. Das Hämoglobin kehrt meist nach 60 Minuten, frühestens nach 30 Minuten, zum Anfungswert zurück und nimmt langsam ab. Das Serumeiweiss kehrt nach 20-30 Minuten zum Anfangswert zurück und nimmt dann auch langsam ab. Wenn man diese Ergebnisse mit denen bei Paraffininjektion vergleicht, so ist der Zunahmegrad des Serumeiweisses noch kleiner als der des Hümoglobins. Das Serumkochsalz hat Neigung, mehr oder minder zuzunchmen.

\section{Einfluss der Einschräkiung der Atem fäche auf das} Gesamtblutrolum.

Um den Grund der Zunahme des Hïmoglobins resp. des Serumeiweisses, die man oben gleich nach der Einschränkung der $A$ temflüche beobachtete, klar zu stellen, habe ich das Gesamtblutvolum vor und nach derselben Operation bestimmt (Tab. 8 a u. b).

Tabelle 8 a.

Verïnderung des Gesantblutvolums durch Anlegen des Paraffinothorax.

\begin{tabular}{|c|c|c|c|c|}
\hline \multirow[b]{2}{*}{ Nr. } & \multirow{2}{*}{$\begin{array}{c}\text { Körpergewicht } \\
\text { (kg) u. } \\
\text { Geschlecht }\end{array}$} & \multirow{2}{*}{$\begin{array}{l}\quad \text { Zeit } \\
\text { yor od. nach } \\
\text { d. Operation } \\
\text { (Min.) }\end{array}$} & \multicolumn{2}{|c|}{ Gesamtblutvolum } \\
\hline & & & $\operatorname{con}$ & $\begin{array}{c}\text { Differenz } \\
\text { in } \%\end{array}$ \\
\hline 1 & $1,750 \quad \hat{\partial}$ & $\begin{array}{l}\text { Vor } \\
\text { Nach } 5\end{array}$ & $\begin{array}{l}80,0 \\
68,5\end{array}$ & $-14,3$ \\
\hline 2 & $1,850 \quad \delta$ & $\begin{array}{l}\text { Vor } \\
\text { Nach } 5\end{array}$ & $\begin{array}{l}98,8 \\
85,4\end{array}$ & $-13,5$ \\
\hline
\end{tabular}




\begin{tabular}{|c|c|c|c|c|c|}
\hline \multirow{2}{*}{ Nr. } & \multirow{2}{*}{\multicolumn{2}{|c|}{$\begin{array}{c}\text { Körpergewicht } \\
\text { (kg) u. } \\
\text { Geschlecht }\end{array}$}} & \multirow{2}{*}{$\begin{array}{l}\text { Zeit } \\
\text { vor od. nach } \\
\text { d. Operation } \\
\text { (Min.) }\end{array}$} & \multicolumn{2}{|c|}{ Gesamtblutrolum } \\
\hline & & & & $\mathrm{ccm}$ & $\begin{array}{c}\text { Differenz } \\
\text { in } \%\end{array}$ \\
\hline 3 & 1,790 & $\hat{0}$ & $\begin{array}{l}\text { Vor } \\
\text { Nach } 5\end{array}$ & $\begin{array}{l}89,2 \\
78,0\end{array}$ & $-12,6$ \\
\hline 4 & 1,800 & $\hat{o}$ & $\begin{array}{l}\text { Vor } \\
\text { Nach } 10\end{array}$ & $\begin{array}{l}89,8 \\
77,9\end{array}$ & $-13,3$ \\
\hline 5 & 1,760 & $\hat{3}$ & $\begin{array}{l}\text { Vor } \\
\text { Nach } 10\end{array}$ & $\begin{array}{l}86,4 \\
78,6\end{array}$ & $-9,0$ \\
\hline 6 & 1,830 & 6 & $\begin{array}{l}\text { Vor } \\
\text { Nach } 10\end{array}$ & $\begin{array}{l}97,9 \\
86,9\end{array}$ & $-11,2$ \\
\hline 7 & $1, \$ 00$ & 우 & $\begin{array}{l}\text { Vor } \\
\text { Nach } 10\end{array}$ & $\begin{array}{l}92,3 \\
\$ 4,3\end{array}$ & $-8,7$ \\
\hline 8 & 1,740 & $\hat{\delta}$ & $\begin{array}{l}\text { Vor } \\
\text { Nach } 30\end{array}$ & $\begin{array}{l}82,3 \\
72,7\end{array}$ & $-11,7$ \\
\hline 9 & 1,780 & $\hat{0}$ & $\begin{array}{l}\text { Vor } \\
\text { Nach } 30\end{array}$ & $\begin{array}{l}90,9 \\
80,6\end{array}$ & $-11,3$ \\
\hline 10 & 1,700 & $\hat{\delta}$ & $\begin{array}{l}\text { Vor } \\
\text { Nach } 30\end{array}$ & $\begin{array}{l}S 0,8 \\
69,0\end{array}$ & $-14,6$ \\
\hline 11 & 1,770 & $\hat{b}$ & $\begin{array}{l}\text { Vor } \\
\text { Nach } 30\end{array}$ & $\begin{array}{l}88,0 \\
73,1\end{array}$ & $-16,9$ \\
\hline 12 & 2,390 & 9 & $\begin{array}{l}\text { Vor } \\
\text { Nach } 120\end{array}$ & $\begin{array}{l}146,7 \\
122,0\end{array}$ & $-16,8$ \\
\hline 13 & 2,360 & f & $\begin{array}{l}\text { Vor } \\
\text { Nach } 120\end{array}$ & $\begin{array}{l}120,3 \\
107,6\end{array}$ & $-10,6$ \\
\hline 14 & 2,700 & s: & $\begin{array}{l}\text { Vor } \\
\text { Nach } 120\end{array}$ & $\begin{array}{l}139,1 \\
113,0\end{array}$ & $-18,8$ \\
\hline
\end{tabular}

Tubelle $8 \mathrm{~b}$.

Verïnderung des Gesamtblutvolums durch Ausschaltung einer Lunge.

\begin{tabular}{|c|c|c|c|c|}
\hline \multirow[b]{2}{*}{ Nr. } & \multirow{2}{*}{$\begin{array}{c}\text { Körpergewicht } \\
\text { (kg) u. } \\
\text { Geschlecht }\end{array}$} & \multirow{2}{*}{$\begin{array}{l}\text { Zeit } \\
\text { vor od. nach } \\
\text { d. Operation } \\
\text { (Min.) }\end{array}$} & \multicolumn{2}{|c|}{ Gesamtblutvolum } \\
\hline & & & $\mathrm{cem}$ & $\begin{array}{c}\text { Differenz } \\
\text { in } \%\end{array}$ \\
\hline 1 & $1,700 \quad 6$ & $\begin{array}{l}\text { Vor } \\
\text { Nach } 5\end{array}$ & $\begin{array}{l}86,0 \\
75,4\end{array}$ & $-12,3$ \\
\hline 2 & $2,605 \quad$ & $\begin{array}{l}\text { Vor } \\
\text { Nach } 5\end{array}$ & $\begin{array}{r}106,7 \\
89,0\end{array}$ & $-11,0$ \\
\hline 3 & $2,700 \&$ & $\begin{array}{l}\text { Vor } \\
\text { Nach } 5\end{array}$ & $\begin{array}{l}120,1 \\
100,3\end{array}$ & $-16,5$ \\
\hline
\end{tabular}




\begin{tabular}{|c|c|c|c|c|c|}
\hline \multirow{2}{*}{ Nr. } & \multirow{2}{*}{\multicolumn{2}{|c|}{$\begin{array}{c}\text { Körpergewicht } \\
\text { (kg) u. } \\
\text { Geschlecht }\end{array}$}} & \multirow{2}{*}{$\begin{array}{l}\text { Zeit } \\
\text { vor od. nach } \\
\text { d. Operation } \\
\text { (Min.) }\end{array}$} & \multicolumn{2}{|c|}{ Gesantblutvolum } \\
\hline & & & & $\mathrm{cm}$ & $\begin{array}{l}\text { Differenz } \\
\text { in } \%\end{array}$ \\
\hline 4 & 1,750 & 甲 & $\begin{array}{l}\text { Vor } \\
\text { Nach } 10\end{array}$ & $\begin{array}{l}86,4 \\
77,0\end{array}$ & $-10,9$ \\
\hline 5 & 1,850 & 3 & $\begin{array}{l}\text { Vor } \\
\text { Nach } 10\end{array}$ & $\begin{array}{l}93,0 \\
84,9\end{array}$ & $-8,7$ \\
\hline 6 & 2,000 & $q$ & $\begin{array}{l}\text { Vor } \\
\text { Nach } 30\end{array}$ & $\begin{array}{l}96,2 \\
87,9\end{array}$ & $-8,6$ \\
\hline $\bar{i}$ & 1,860 & $\delta$ & $\begin{array}{l}\text { Vor } \\
\text { Nach } 30\end{array}$ & $\begin{array}{l}99,4 \\
86,1\end{array}$ & $-13,4$ \\
\hline 8 & 1,880 & 3 & $\begin{array}{l}\text { Vor } \\
\text { Nach } 30\end{array}$ & $\begin{array}{l}118,8 \\
106,0\end{array}$ & $-10,8$ \\
\hline 9 & 2,100 & P & $\begin{array}{l}\text { Vor } \\
\text { Nach } 120\end{array}$ & $\begin{array}{r}110,5 \\
93,6\end{array}$ & $-15,3$ \\
\hline 10 & 2,450 & 3 & $\begin{array}{l}\text { Vor } \\
\text { Nach } 120\end{array}$ & $\begin{array}{l}130,6 \\
115,7\end{array}$ & $-11,4$ \\
\hline 11 & 3,200 & 7 & $\begin{array}{l}\text { Vor } \\
\text { Nach } 120\end{array}$ & $\begin{array}{l}187,8 \\
155,1\end{array}$ & $-17,4$ \\
\hline
\end{tabular}

Wie aus Tab. 8 erhellt, findet man bei künstlichem Paraffinothorax resp. bei der Ausschaltung der cinseitigen Lunge nach je 5, 10, 30 und 120 Min. in jedem Falle ausnahmslos Abnahme des Grsamtblutvolums, d. h. Einschränkung der A temflüche ruft Abnahme des Gesamtblutvolums bzw. der Kapazität des Gefüsses hervor.

\section{Zusammenfassung und kritische Besprechung.}

Alles oben Beschriebene sei folgendermassen zusammengefasst. Bei der Injektion von Paraffinum fluidum in die Pleurahöhle normaler Kaninchen nehmen Hümoglobin- und Serumeiweissgehalt sofort nach der Einspritzung zu. Dies beweist die Eindickung des Bluts gleich nach der Operation, die sich aber allmählich wiederherstellt, und später wird das Blut im Gegenteil verdünnt. Das Serumeiweiss hat einen relativ geringeren Grad der Zunahme als das Hämoglobin. Auch bei der Ausschaltung der einseitigen Lunge haben beide fast die gleiche Neigung, nur dass auch hier das Serumeiweiss weit weniger zunimmt.

Wenn man diese Verhältnisse an Uran- und Cantharidinkaninchen beobachtet, so nimmt Ḧ̈moglobin bei künstlichem Paraffinothorax auf- 
fallend zu, während die Zunahme des Serumeiweisses bedeutend kleiner ist. Und ungeachtet wiederholter Blutentnahmen besteht die Steigerung der Hämoglobin- und Serumeiweisskonzentration etwas länger als bei Kaninchen in gesundem Zustand. Auch bei Ausschaltung der einseitigen Lunge findet man ähnliche Verhältnisse, aber im Vergleich mit den Fällen bei künstlichem Paraffinothorax ist der Grad der Zunahme des Serumeiweisses noch kleiner als der des Hämoglobins. Bei Uran- und Cantharidinkaninchen ist die Zunahme des Hïmoglobins auffallender als bei gesunden Kaninchen, während die des Serumeiweisses relativ kleiner ist. Besonders diese Verhältnisse sind bei Cantharidintieren ausgesprochener.

Die Veränderungen des Serumkochsalzes sind gering ; gleich nach Beschränkung der Atemfläche nimmt es ein wenig zu, und später, mit der Abnahme des Hämoglobins, neigt es mehr oder minder zur Zunahme.

Wenn man nun die Veränderungen des Gesamtblutvolums bei Einschränkung der Atemfläche beobachtet, so nimmt es sowohl bei künstlichem Paraffinothorax als auch bei Ausschaltung der einseitigen Lunge ausnahmslos ab.

Also wird nach Einschränkung der Atemfläche das Blut zuerst eingedickt und dann allmählich verdünnt. Diese Verdünnung sollte man, wie bei der methodischen Betrachtung der Kontrollfülle, als die Folge der An̈̈mie durch die neunmaligen Blntentnahmen betrachten. Deshalb wäre die eigentliche Veränderung, die durch Einschränkung der Atemfläche eintritt, in dieser Bluteindickung zu schen.

Was den Mechanismus der Bluteindickung überhaupt anbetrifft, so muss er hauptsächlich im Verlust des im Blut enthaltenen Wassers aus dem Gefüss hinaus bestehen, mag dies ins Gewebe hinein, oder direkt aus dem Körper hinaus treten. Ausserdem wäre noch daran zu denken, dass sich im Blut Blutelemente neubilden oder aus einem sogenannten Blutreservoir, wie der Milz, ins zirkulierende Blut treten. Stäubli, ${ }^{5)}$ Wanner, ${ }^{61}$ Seyderhelm, ${ }^{7}$ Kaulen, ${ }^{8)}$ Hirschlaf, ${ }^{92}$ Hasselbach, ${ }^{10)}$ Detre, ${ }^{11)}$ Detre und Mirgay, ${ }^{12)} \mathrm{Kuhn}^{13)}$ u. a. meinen, dass bei $\mathrm{O}_{2}$-Mangel das Knochen-

5) Stäubli, Verhandlungen des Kongress. f. innere Med., 1910, 27, 695.

6) Wa nner, Correspondenz-Blatt $\mathrm{f}$. Schweizer Aerzte, 1918, 43, 941.

7) Seyderhelm, Deutsch. med. Wochenschr., 1916, 1245.

8) Kaulen, Deutsch. med. Wochenschr., 1917, 1562.

9) Hirschlaf, Berl. klin. Wochenschr., 1917, 1562 .

10) Hasselb ach, Biochem. Zeitschr., 1916, 74, 48.

11) Detre, Zeitschr. f. d. ges. ex.p. Med., 1927, 56, 76.

12) Detre und Mirga y, Med. Klinik, 1928, 1628.

13) Kubn, Münch. med. Wochen chr, 1907, 1713. 
mark gereizt und Polycythämie hervorgerufen wird. Wenn man aber die oben erwähnten Ursachen der Bluteindickung betrachtet, so muss die Blutmenge bei der ersteren Ursache abnehmen, wïhrend sie bei der letzteren unverändert bleiben oder im Gegenteil ein wenig zunehmen muss. Bei der Untersuchung des Gesamtblutvolums fand ich in allen Versuchen ausnahmslos Verminderung. Daraus folgt, dass diese Bluteindickung nicht durch die letztere, sondern durch die erstere Ursache hervorgerufen werden muss. Aus der in der folgenden Mitteilung zu erörternden Tatsache, dass man dabei keine junge Form der Erythrozyten finden kann, folgt überdies, dass dies unwichtig sein muss, mag auch der Einfluss solches Falitors vorhanden sein.

Von dem Mechanismus, durch den in meinem Experimente das Gefäss Wasser verliert, kommen hauptsächlich zwei Faktoren in Betracht, Asphyxie und Einschränkung des klcinen Kreislaufs. Dazu muss man noch die Steigerung der Verdunstung des Blutwassers aus der Lunge wegen Dyspnoë rechnen.

Was die Asphyxie betrifft, so hat $\mathrm{Okada}^{14)}$ in unserer Klinik $\mathrm{Ab}$ nahme des osmotischen Drucks des Blutkolloids gefunden, indem er Kaninchen Luft mit $8 \%$ Sauerstoffgehalt einatmen liess und den osmotischen Druck des Blutkolloids bei konstantem $\mathrm{O}_{2}$-Mangel bestimmte. Diese Esscheinung kann man da wahrnehmen, wo Wasser aus dem Gefässe ins Gewebe tritt. Folglich könnte man auch mein Experiment dahin erklären, dass die Zunahme des Hämoglobins und Sarumeiweisses durch das Heraustreten des Wassers aus dem Gefïsse ins Gewebe hervorgerufen wird. $\mathrm{Er}$ hat sich herausgestellt, dass die Zunahme des Serumeiweisses im Vergleich zu der des Hämoglobins relativ gering ist. An dieser Tatsache kann man erkennen, dass das Eiweiss, dessen Molekül kleiner ist, durch die Gefässwand hinaustritt, und der Eiweisskörper, dessen Molekül relativ grösser ist, im Blut bleibt, folglich der kolloidosmotische Druck sinkt.

In Bezug auf die Durchlässigkeit der Gefässwand für das Serumeiweiss hat $\mathrm{Na}$ i to ${ }^{15)}$ u. a. durch Tierexperiment bestätigt, dass Eiweisskörper durch die beschädigte Kapillarwand lebhaft ein- und austreten, auch haben Mo rawitz und Deneck $\mathrm{e}^{16)}$ durch Untersuchung der Gefüssfunktionen verschiedener Nierenleiden, des Scharlachs u. a. gefunden, dass die Kranken verschiedene Durchlïssigkeit der Gefässe für Eiweisskörper besitzen. Mag-

14) Okada, Nippon-Naika-Gakkai-Zasshi, 1929, 17, 170.

15) Naito, Tohoku Journ. Exp. Med., 1924, 5, 351.

16) Morawitz und Denecke, Münch. med. Wochenschr., 1921, 659. 
nus, ${ }^{17)}$ Nonnenoruch, ${ }^{18) 193203}$ Samson, ${ }^{21)}$ Gottschalk und Nonnen$\mathrm{bruch}^{22)}$ u. a. meinen, dass auch normale Kapillaren, unter gewissen Bedingungen, für Eiweisskörper durchlüssig sein können. Dass sich durch Asphyxie des peripheren Gewebes die Permeabilitüt der Gefässwand verändert, ist allgemein anerkannt (Loeb, ${ }^{23)} \mathrm{F}$ ischer, $\left.{ }^{2+7}\right) \mathrm{Yamaguch} \mathrm{i}^{(25)}$ ). In meinen Experimenten muss durch plötzliche Verkleinerung der Atemfläche in den Zellen des Gewebes oder noch dazu in denen der Getässwand augenblicklich mehr oder minder starke Asphyxie hervorgerufen werden können, wodurch die Permeabilität verändert wird, folglich das Blut sowohl Wasser als auch Eiweisskörper ins Gewebe verliert. Dass die Zunahme des Hämoglobins grösser als die des Serumeiweisses ist, beweist, dass nicht nur Wasser, sondern auch mehr oder weniger Serumeiweiss aus dem Gefässe tritt. Überdies ruft das Komprimieren der betreffenden Lunge oder das Erschweren der Blutdurchströmung bei künstlichem Paraffinothorax resp. bei der Ausschaltung der einseitigen Lunge Abnahme der Kapazität des Gefässes hervor, wodurch sich natürlich der Filtrationsdruck steigert, was zusammen mit der gesteigerten Durchlässigkeit der Gefässwand Bluteindickung verursacht.

Durch Dyspnoë steigert sich sowohl die Atemzahl als auch die Atemgrösse und vermehrt sich die Verdunstung des Wassers aus der Lunge ; dies ist auch eine Ursache der Bluteindickung. Aber die Tatsache, dass die Zunahme der Serumeiweisses kleiner als die des Hümoglobins ist, weist darauf hin, dass Blut nicht nur Wasser, sondern auch Eiweisskörper aus sich verliert, also anch, dass die Bluteindickung nicht nur aus der Verdunstung des Wassers aus der Lunge herkommt. Da sich in meinen Experimenten die Atemfläche rasch beinahe bis zur Hälfte verkleinert, so dürfte wohl der Mechanismus der Bluteindickung durch Verdunsten nicht in Betracht kommen.

Die Ursache, warum bei Uran- und Cantharidinkaninchen die $\mathrm{Zu}$ nahme des Hämoglobins bedeutender ist, während die des Scrumeiweisses ausgesprochen kleiner ist als bei normalen Kaninchen, muss darin liegen,

17) Magnus, Arch. f. exp. Pathol. und Pharm., 1900, 44, 68.

18) Nonnenbruch, Arch. f. exp. Pathol. u. Pharm., 1921, 91, 218 u. 332.

19) Ders., Klin. Wochenschr., 1922, 2046.

20) Ders., Zeitschr. f. d. ges. exp. Med., 1922, 29, 547.

21) Samson, Biochem. Zeitschr., 1921, 118, 55.

22) Gottschalk und Nonnenbruch, Arch. f. exp. Pathol. u. Pharm., 1923, 96, 115.

23) Loeb, Pflügers Arch., 1898, 71, 459.

24) Fischer, Oedema and Nephritis, New York 1915.

25) Yamaguchi, Tohoku Journ. Exp. Med., 1927, 8, 449. 
dass vermöge jener Gifte die Veränderung der Permeabilität der Gefässwand für Wasser sowie für Eiweisskörper und auch die Veründerung der Eigenschaft des Gewebes selbst noch dentlicher wird. Dies ist nach den Experimenten $\mathrm{Naitos}$ und $\mathrm{Yamaguch}$ is in unserer Klinik sicher.

1. Einschränkung der Atemflüche (Anlegen künstliches Paraffinothorax oder Ausschaltung der einseitigen Lunge) bei normalen Kaninchen ruft Bluteindickung hervor. Bei Einschränkung der Atemfläche des Uranund Cantharidinkaninchens ist die Blutveränderung ähnlich, aber ihr Grad etwas höher.

Beim Vergleich der Veränderung der Konzentration des Hümoglobins mit der des Serumeiweisses findet sich auffallende Zunahme des ersteren, jedoch geringe des letzteren. Besonders bei Uran- und Cantharidinkanin sind diese Verhältniese dentlich. Und die prozentuelle Zunahme des Serumeiweisses bei Ausschaltung der einseitigen Lunge ist niedriger als bei künstlichem Paraffinothorax.

Obgleich die Veränderung des Serumkochsalzes kleiner ist, so nimmt es doch gleich nach der Einschränkung der A temflüche ein wenig zu, später hat es bei Abnahme des Hämoglobins die Neigung, mehr oder weniger zuzunehmen.

Nach der Einschränkung der A temfläche kann man die Abnahme des Gesamtblutvolums in allen Fällen nachweisen.

2. Die obige Veränderung der Blutkonzentration erfolgt hauptsächlich durch die Veränderung der Permeabilität der Gefässwand infolge der Atemstörung, teils aber auch durch die Zunahme des Filtrationsdrucks im Blutkreislauf durch Einschränkung des kleinen Kreislaufs. Diese Veränderung der Blutkonzentration ist bei solchen Tieren besonders stark, deren Gefässpermeabilität oder Körpergewebe vorher durch Nieren- bzw. Vornierengift verändert worden ist. 